\title{
LAJEADO ONLINE - OBJETOS DE APRENDIZAGEM COMO PROPOSTA DIDÁTICA NO MUNICÍPIO DE LAJEADO/RS
}

\author{
Fernando de Oliveira ${ }^{1} \&$ Ivaine Maria Tonini ${ }^{2}$ \\ ${ }^{1}$ Mestre em Geografia/Educação pela Universidade Federal do Rio Grande do Sul. E-mail: nando.oli.geo@gmail.com.
}

Recebido em 07/2013. Aceito para publicação em 10/2013.

Versão online publicada em 19/09/2014 (http://seer.ufrgs.br/paraonde)

\begin{abstract}
Resumo - Este artigo teve como intenção central mostrar Objetos de Aprendizagem com temáticas direcionadas para o estudo da cidade para possibilitar atividades didáticas em uma sala de aula online no ensino de Geografia da educação básica. 0 referencial teórico permitiu o entendimento deste recurso como uma ferramenta interativa entre aluno e conhecimento, no qual se torna produtor de seu saber. Os resultados indicam a relevância do uso dos Objetos de aprendizagem em sala de aula, não somente por ser uma ferramenta de ampla operacionalidade nas práticas cotidianas dos alunos, mas como aumento do interesse dos alunos em buscar e construir conhecimento do seu cotidiano.
\end{abstract}

Palavras-chave: objetos de aprendizagem, educação online, cidade, ensino de Geografia.

\section{Das primeiras conectadas}

As aulas de Geografia conectadas à internet são mais simples do que os professores imaginam. Políticas públicas vêm, desde a década de 1990, ofertando novas possibilidades em informática com tecnologias de imagem e localização e apoiam iniciativas nas quais a computação é utilizada na escola. Em tempos mais recentes, ferramentas de livre acesso de companhias privadas possibilitam novas práticas online. E por que o professor resiste, não utiliza ou não se interessa por saber usar estas possibilidades? Soa estranha esta atitude já que na sua vida fora da escola a maioria dos professores usa celulares, e-mail, câmaras digitais e, muitos, até são usuários de redes sociais. No entanto, trazê-las para a sala de aula é uma atitude pouco presente.

Hoje, o acesso à internet no Brasil é de 40,56\% ${ }^{1}$, porém nas escolas esse índice é inferior. Embora 81\% das escolas públicas do Brasil possuam laboratórios de informática, apenas $4 \%$ delas disponibilizam acesso à ferramenta em sala de aula ${ }^{2}$. De certa forma, o investimento das escolas na infraestrutura de informática não tem tido resultados esperados. No entanto, para os alunos, a escolha entre a aula tradicional e a aula com internet é clara: ganha aquela que mais se atualiza e que é mais atrativo. Quanto aos professores, é necessária uma formação direcionada para cursos práticos para ensiná-los a usar a internet em sala de aula.
A prática do uso da internet como ferramenta de auxílio na educação é pouco explorada na escola. Assim como um mapa do livro didático, cuja leitura é ensinada pelo professor aos alunos, o uso da internet em sala de aula também precisa ainda ser ensinado ao professor.

Uma prática constante nas escolas é bloquear o acesso a sites de relacionamento pessoal, quando a escola deveria seguir rumo alternativo: instruir o uso de tais ferramentas para construção do conhecimento. A mudança do ponto de vista em relação às tecnologias digitais precisa ser (re)construída em direção a um futuro de aliança com o ensino, não como uma concorrente como tem sido entendida pela maioria das escolas.

Neste sentido, fazemos algumas indagações: Como a internet é utilizada pelo professor na sala de aula atualmente? Que ferramenta de ensino pode ser construída para auxiliar no processo de ensino sem roubar espaço da figura do professor? Como utilizar a rede mundial de computadores de forma colaborativa na educação? É possível tornar a educação mais dinâmica com a utilização de Objetos de Aprendizagem $(\mathrm{OAs})^{3}$ ? Qual o ganho de qualidade que se tem ao construir um OA em conjunto com professores, pesquisadores e programadores?

Com estas perguntas pensamos que um dos encaminhamentos para inserção das tecnologias digitais seria proporcionar uma ferramenta digital interativa, mas que não seja apenas uma plataforma em que o conteúdo a ser trabalhado seja para se assistir, mas planejado para

\footnotetext{
${ }^{1}$ Fundação Instituto Brasileiro de Geografia e Estatística (FIBGE), 2010.

${ }^{2}$ Centro de Estudos sobre das Tecnologias da Informação e da Comunicação (CETIC), 2011. Criado em 2005, é um departamento do Núcleo de Informação e Coordenação do Ponto BR (NIC.br) responsável pela coordenação e publicação de pesquisas sobre a disponibilidade e uso da Internet no Brasil. ${ }^{3}$ Para Handa e Silva $(2003,5)$ objeto de aprendizagem (OA) pode ser "um arquivo digital (imagem, filme, etc.) que pretende ser utilizado para fins pedagógicos e que possui, internamente ou através de associação, sugestões sobre o contexto apropriado para sua utilização".
} 
arquitetar percursos que supõem autoria e colaboração dos alunos para construção do conhecimento.

Esta arquitetura de sala de aula permite maior participação dos alunos através das suas intervenções tornando uma sala de aula interativa, onde conforme Silva (2012, p. 72) "a participação do aluno se inscreve nos estados potenciais do conhecimento arquitetados pelo professor de modo que evoluam em torno do núcleo planejado com coerência e continuidade". Logo, a importância do professor é sobressaltada, sendo essa uma das metas de um processo onde a educação não compete com a tecnologia, mas sim, alia-se a ela.

A partir dessas reflexões, elaboramos alguns OAs que permitem ao aluno deixar de ser um usuário-consumidor daquilo que é disponibilizado online para ser um usuário-produtor e participante ativo na construção das informações e conteúdos disponibilizados na rede. Para tanto a proposta metodológica teve como objetivos: estudar o entendimento de sala de aula interativa através do uso de tecnologias digitais com a finalidade de compreender a educação online como elemento estruturante pra construção do conhecimento; refletir sobre o uso das tecnologias como elemento estruturante para construção do conhecimento em sala de aula e elaborar OAs com a intenção de contribuir para a criação de sala de aula online.

\section{Dos Objetos de Aprendizagem e práticas didáticas}

A informática como ferramenta auxiliar na educação no Brasil vem se inserindo desde a década de 1980 através de jogos e ferramentas educativas. Na década de 1990, o advento da internet trás a digitalização dos conteúdos impressos disponibilizada na rede mundial de computadores, amedrontando professores e criando uma grande expectativa frente a essas tecnologias. De lá para cá, pouca coisa mudou no discurso pedagógico, ao passo que muito se cumpriu diante da expectativa às tecnologias.

Entramos no século XXI e as possibilidades do meio digital se ampliaram a partir das redes formadas pela internet nos diversos meios onde ela é utilizada. A economia, a política e os interesses sociais são compartilhados intensamente na rede mundial de computadores. Já na segunda década deste novo século, a utilização das redes sociais para a divulgação e compartilhamento de informações expande seus horizontes vertiginosamente. Contudo, quando pensamos a internet e o uso das redes sociais para e a partir da educação, especialmente no Brasil, não temos presenciado grandes movimentos entre as escolas, alunos e professores. Conforme Behar $(2009,78)$, "à medida que vão aparecendo no mercado novas tecnologias, elas vão sendo incorporadas ao sistema educacional, fazendo com que as questões de Ensino a Distância (EAD) sejam olhadas mais do ponto de vista tecnológico do que pedagógico", trazendo resultados negativos ao ensino por uma confusão de foco: a tecnologia, ao invés dos paradigmas.

As ferramentas digitais merecem estar presentes na escola, pois contribuem, conforme Sampaio (2011) para: a) diversificar as formas de atingir o conhecimento; b) ser estudadas, como objeto e como meio de se chegar ao conhecimento, já que trazem embutidas em si mensagens e um papel social importante; c) permitir ao aluno, através da utilização da diversidade de meios, familiarizar-se com a gama de tecnologias existente na sociedade; d) serem desmistificadas e democratizadas. Logo, sabemos que a tarefa de arquitetar e construir uma ferramenta digital vai muito além de uma simples digitalização de conteúdo. De tal modo que "a tecnologia é uma parceira para promoção de uma educação como forma de liberação e de libertação do homem" e, nestes novos processos educativos, "não há possibilidade para práticas tradicionais de transmissão de informação pronta e de verdades absolutas" (ASSMANN, 2005, 125).

Os OAs são ferramentas ${ }^{4}$ online, ou não, para auxiliar o processo de automação do ensino e aprendizagem. Embora seja uma ferramenta recente para auxiliar o processo de aprender, já existem estudos e conclusões sobre sua validade neste processo. Analisando as possibilidades e o que já foi construído até agora, pode-se dizer que os OAs se tornaram uma ferramenta em potencial no auxílio ao educador e de contribuição ao processo de compreensão de conteúdos. Porém, os diversos conceitos apresentados nos levam a discutir a operacionalidade dos mesmos, bem como a efetividade prática dos OAs.

Em Handa e Silva (2003), encontramos o conceito de OAs do Institute of Eletrical and Eletronic Engineers (IEEE):

o Objeto de Aprendizagem é definido como uma entidade, digital ou não-digital, que pode ser usada, re-usada ou referenciada durante o ensino com suporte tecnológico. Exemplos de ensino com suporte tecnológico incluem sistemas de treinamento baseados no computador, ambientes de aprendizagem interativa, sistemas instrucionais auxiliados por computador, sistemas de ensino a distância e ambientes de aprendizagem colaborativa. Exemplos de Objetos de Aprendizagem incluem conteúdo multimídia, conteúdos instrucionais, objetivos de ensino, software instrucional e software em geral e pessoas, organizações ou eventos referenciados durante um ensino com suporte tecnológico (p.1).

Para os autores, porém, essa delimitação de objeto de aprendizagem é muito abrangente, pois torna qualquer material de ensino com alguma base tecnológica um objeto de aprendizagem, seja ele online ou não.

Handa e Silva (2003) nos trazem outra definição,

${ }^{4}$ Utilizo o sinônimo ferramentas como auxílio ao termo TIC’s 
um pouco mais pontual, de objeto de aprendizagem, sendo que "objeto de aprendizagem é um arquivo digital (imagem, filme, etc.) que pretende ser utilizado para fins pedagógicos e que possui, internamente ou através de associação, sugestões sobre o contexto apropriado para sua utilização". Pode-se perceber aqui uma aproximação ao uso de links e/ou hipertextos, ou pelo menos a associação e importância deste para os OAs, visto que ambos levam usuário da web a se deslocar do ambiente digital ${ }^{5}$ de origem para um sem-limites número de outros ambientes digitais.

Tarouco e Cunha (2006) abordam de forma sucinta a estrutura de um objeto de aprendizagem, ou seja, as necessidades que eles precisam ter na hora de seu planejamento. Um OA deve conter três partes:

[...] os objetivos: esta parte do objeto tem como intenção demonstrar ao aprendiz o que ele poderá aprender a partir do estudo desse objeto, também poderá conter uma lista dos conhecimentos prévios necessários para um bom aproveitamento de todo o conteúdo disponível; conteúdo instrucional: aqui deverá ser apresentado todo o material didático necessário para que no término o aluno possa atingir os objetivos citados no item anterior; prática e realimentação: uma das características importantes do paradigma objetos de aprendizagem é que a cada final de utilização julga-se necessário que o aprendiz verifique se o seu desempenho atingiu as expectativas, caso não, $\mathrm{o}$ aprendiz deve ter a liberdade para voltar a utilizar-se do objeto quantas vezes julgar necessário (p.3).

Ainda Tarouco e Cunha (2006) indicam três questões a serem feitas anteriormente à construção de um objeto de aprendizagem, sendo elas: "[...] o que o aluno sabe; o que vai poder conhecer; o que poderia ser um ponto de entrada para uma experiência de aprendizagem". É então questionado "quais são os componentes de ação de um objeto de aprendizagem; qual conteúdo é abordado em um objeto de aprendizagem; como é organizado um objeto de aprendizagem" (p. 6).

Oito critérios podem ser seguidos na construção de um OA como foi listado por Behar (2009) de acordo com Hack (2006). São eles: i) condução, para orientar o usuário no uso do ambiente virtual; ii) carga de trabalho, controlando a quantidade de informações passadas ao usuário; iii) controle explícito, feito pelo usuário e efetivadas pelo sistema; iv) adaptabilidade, contextualizando a interface de acordo com o usuário; v) gestão de erros, com prevenção do sistema para possíveis erros; vi) consistência, para manter um padrão de interface e textos em todos os ambientes do OA; vii) expressividade, onde os símbolos usados condizem com o usuário; viii) compatibilidade, entre o sistema e os usuários. Pode-se fazer desse check-list um roteiro inicial e final na criação de um OA.

Finalizamos com o conceito de objeto de aprendizagem proposto por Audino ${ }^{6}$ e Nascimento (2010), que define os OAs como sendo

recursos digitais dinâmicos, interativos e reutilizáveis em diferentes ambientes de aprendizagem elaborados a partir de uma base tecnológica. Desenvolvidos com fins educacionais, eles cobrem diversas modalidades de ensino: presencial, híbrida ou a distância; diversos campos de atuação: educação formal, corporativa ou informal; e, devem reunir várias características, como durabilidade, facilidade para atualização, flexibilidade, interoperabilidade, modularidade, portabilidade, entre outras. Eles ainda apresentam-se como unidades auto consistentes de pequena extensão e fácil manipulação, passiveis de combinação com outros objetos educacionais ou qualquer outra mídia digital (vídeos, imagens, áudios, textos, gráficos, tabelas, tutoriais, aplicações, mapas, jogos educacionais, animações, infográficos, páginas web) por meio da hiperligação. Além disso, um objeto de aprendizagem pode ter usos variados, seu conteúdo pode ser alterado ou reagregado, e ainda ter sua interface e seu layout modificado para ser adaptado a outros módulos ou cursos. No âmbito técnico, eles são estruturas autocontidas em sua grande maioria, mas também contidas, que, armazenadas em repositórios, estão marcadas por identificadores denominados metadados.

Percebo que, ao pesquisar sobre o planejamento, construção e utilização de um $\mathrm{OA}$, muitas tentativas de homogeneizar estes três processos tornam essa ferramenta um tanto quanto monótona. De todos os OAs que já criei/manipulei, a maior parte não consegue atingir as expectativas criadas em cima destas TIC's. Considero como expectativa alcançada: um aluno que se sinta atraído pela reutilização do $\mathrm{AO}$, usando-o para diversos fins; um professor utilizando o OA para atividades com temas diferentes, pois ele é aberto e abrangente; um ambiente digital que concentre o processo de ensino e aprendizagem de forma encantadora.

\section{Dos links da cidade com objetos de aprendizagem}

Uma das primeiras etapas a ser realizada para se escolher a temática de um OA é colocar-se no lugar do aluno e imaginar qual o interesse do mesmo nos diversos assuntos abordados em Geografia. A utilização de exemplos práticos e reais também é fundamental,

${ }^{5}$ Ambiente digital é adotado nesta pesquisa como sinônimo de OA, sites, AVA's, Redes Sociais e outros ambientes online e off-line.

${ }^{6}$ AUDINO, Daniel fez, junto comigo, parte do grupo de criação de OAs em Geografia da Universidade Federal de Santa Maria, entre 2006 e 2008. 
uma vez que o aluno precisa de modelos de realidade para relacionar a um determinado conteúdo. Seguinte a isso, deve haver variadas possibilidades de interação do aluno com o OA, tendo em vista a capacidade de interação fornecida ao aluno por um computador. Castrogiovanni e Costella $(2006,174)$ trazem o espaço vivido como aquele que o aluno "vivencia através do domínio concreto, onde se movimenta, onde ele atua intuitivamente". A busca por um OA que propiciasse um conhecimento global a partir do local foi em direção ao estudo do lugar.

Assim foi pensado em construir as OAs tendo a cidade como local empírico para realizar as atividades desenvolvidas em sala de aula. Tais OAs podem ser usadas em diversos anos do ensino por serem construídas tendo um mapa como tela de fundo, onde a interatividade para o georreferenciamento torna-se possível.

A escolha por um mapa de tela esta por pensarmos que a "a interpretação de um mapa é baseada nas experiências do sujeito que a interpreta, referenciadas, por sua vez, na sociedade em que vive e na sua habilidade cognitiva" (BEHAR, 2009, 25). A autora comenta ainda a utilização da imagem, neste estudo é o mapa, como potencial atrativo dos OAs, porém com valor didático nulo quando a imagem recebe caráter ilustrativo. Assim, o uso do mapa como palco da interatividade coloca o aluno em uma posição de destaque na criação e utilização do OA.

Uma das primeiras etapas a ser realizada para se escolher a temática de um OA é colocar-se no lugar do aluno e imaginar qual o interesse do mesmo nos diversos assuntos abordados em Geografia. A utilização de exemplos práticos e reais também é fundamental, uma vez que o aluno precisa de modelos de realidade para relacionar a um determinado conteúdo. Seguinte a isso, deve haver variadas possibilidades de interação do aluno com o OA, tendo em vista a capacidade de interação fornecida ao aluno por um computador.

Uma paisagem seja de uma rua, de um bairro ou de uma cidade, além de representar uma dimensão concreta e material do mundo, está impregnada de significados que são construídos pela percepção de forma imediata com essas representações sociais. Quando um aluno muda de rua, de escola, de bairro ou de cidade, ele não sente apenas as diferenças das condições materiais nos novos lugares, mas também as mudanças de símbolos, códigos e significados com os lugares.

Isto mostra tamanha importância que tem a escala de estudo para o cotidiano do aluno, por ser no estudo do lugar que ele se amplia a partir do estudo do seus horizontes mais amplos, chegando ao global, pois "o lugar é, portanto, o habitual da vida cotidiana mas, por outro lado, também é por onde se concretizam relações e processos globais. O lugar produz-se na relação do mundial com o local, que é ao mesmo tempo a possi- bilidade de manifestação do global e de realização de resistências à globalização" (CAVALCANTI, 2008, 65).

Também Santos $(1998,112)$ sobre estas reflexões ao afirmar que:

cada localização é, pois, um momento de imenso movimento do mundo, apreendido em um ponto geográfico, um lugar que está sempre mudando de significação em função do movimento social, onde a cada instante as frações da sociedade que lhe cabem são as mesmas. Nesse sentido o lugar é concebido como um espaço em que ocorrem confluências das relações verticais relacionadas às influências externas, ao poder constituído de relações econômicas e culturais em conexão com as relações horizontais que são representadas pela função desempenhada pelos indivíduos e os grupos de interesses às contradições, à resistência.

Por lugar também podemos entender a cidade. 0 estudo da cidade fundamenta essa proposta didática deste estudo, por acharmos importante e necessário para o aluno, na medida em que ele está vivendo o espaço e o tempo da sua cidade. Isto permite que se reflita e busque a compreender todos os elementos da complexidade do lugar. É trabalhar com uma escala geográfica que permite que tenhamos próximos de nós todos aqueles elementos que expressam as condições sociais, econômicas, políticas do nosso mundo.

Com o mapa de tela nos OAs permite ter uma função de amortecedor das reflexões, pois é a partir dele que o aluno vai reconhecer ruas, rios e arroios, a sua escola e demais pontos de referência, e em cima desses inserir/ construir o seu conhecimento, mediado pelo professor.

Para conectar o estudo da cidade aos $\mathrm{OAs}^{7}$ foram construídos dois denominados de "Quebra-cabeça: Bairros de Lajeado/RS" (Imagem 1) e "Lajeado Virtual" (Imagem 2) sem a intencionalidade de fixá-los em algum dos anos da educação básica. Os professores escolherem a aplicação, sendo que tal atitude deve-se a possibilidade da adequação destes OAs em diversos temas relacionadas ao estudo da cidade. Com isto o professor pode selecionar a temática que interessa e operar com os OAs propostos.

O OA Quebra-cabeça: Bairros de Lajeado/RS foi construído com a intenção de se trabalhar com um conteúdo que abordasse mais diretamente o local de vivência do aluno, seu bairro. São infinitas as atividades que podem ser propostas em sala de aula e todas elas lincadas com o cotidiano dos alunos, podem ser inicialmente de localização das ruas, dos elementos físicos da natureza para, posteriormente, estabelecer conexões com as outras escalas geográficas.

O tema para construção deste OA Bairros de Lajeado/RS foi escolhido seguindo sugestão, entre outros,

${ }^{7}$ Para a construções dos OAs foram buscada ajudas de programador de informática. Todas foram realizadas por Rafael Monteiro, da LiquidWorks - soluções em TI/Lageado/RS. Devido ao formato deste arquivo não é possível demosntrar a interatividade dos OAs, mas eles estão disponíveis em: <http:www. lajeadovirtual.com.br>. 


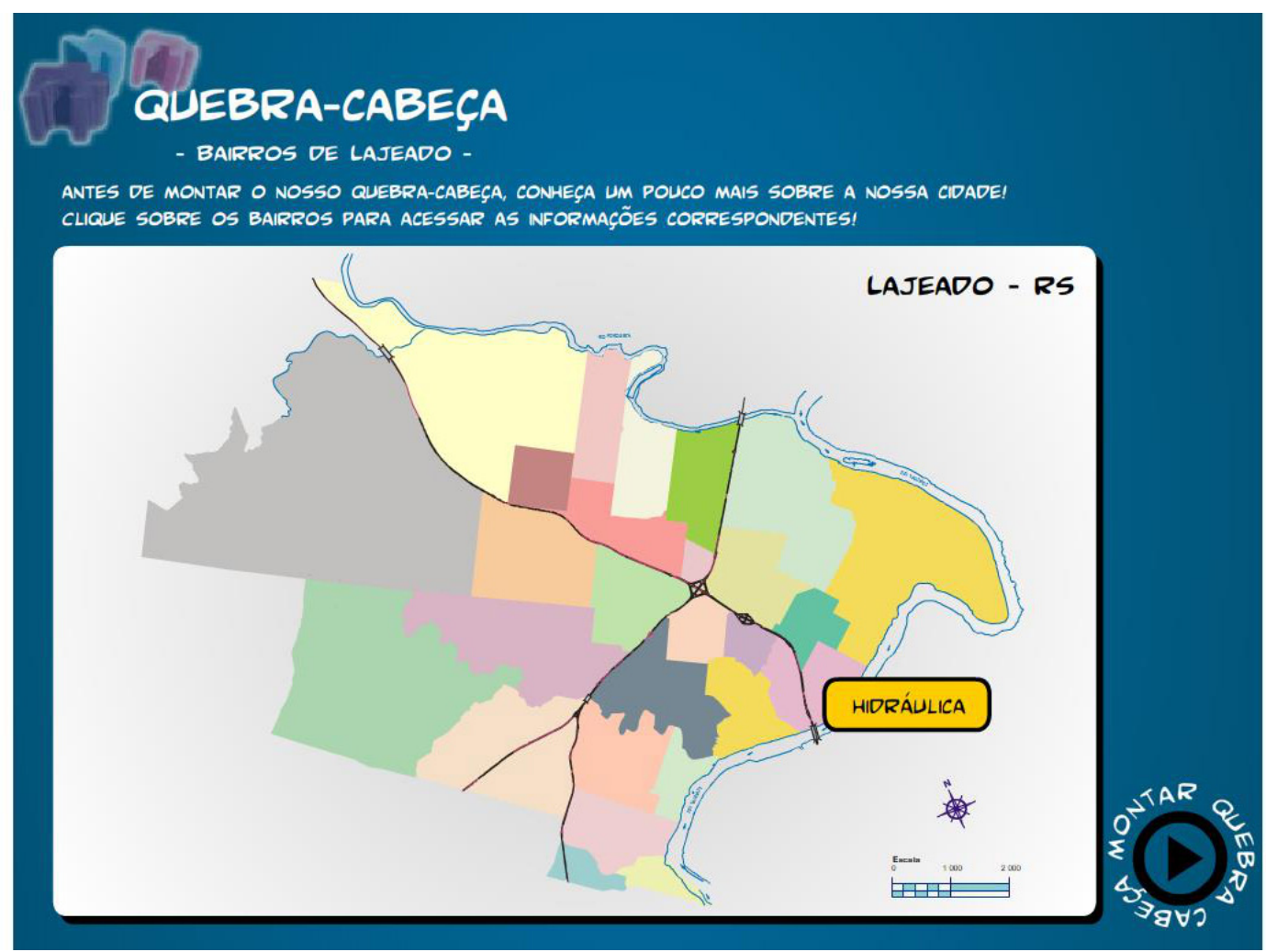

Fonte: OLIVEIRA, 2008.

Imagem 2 - OA Lajeado Virtual.

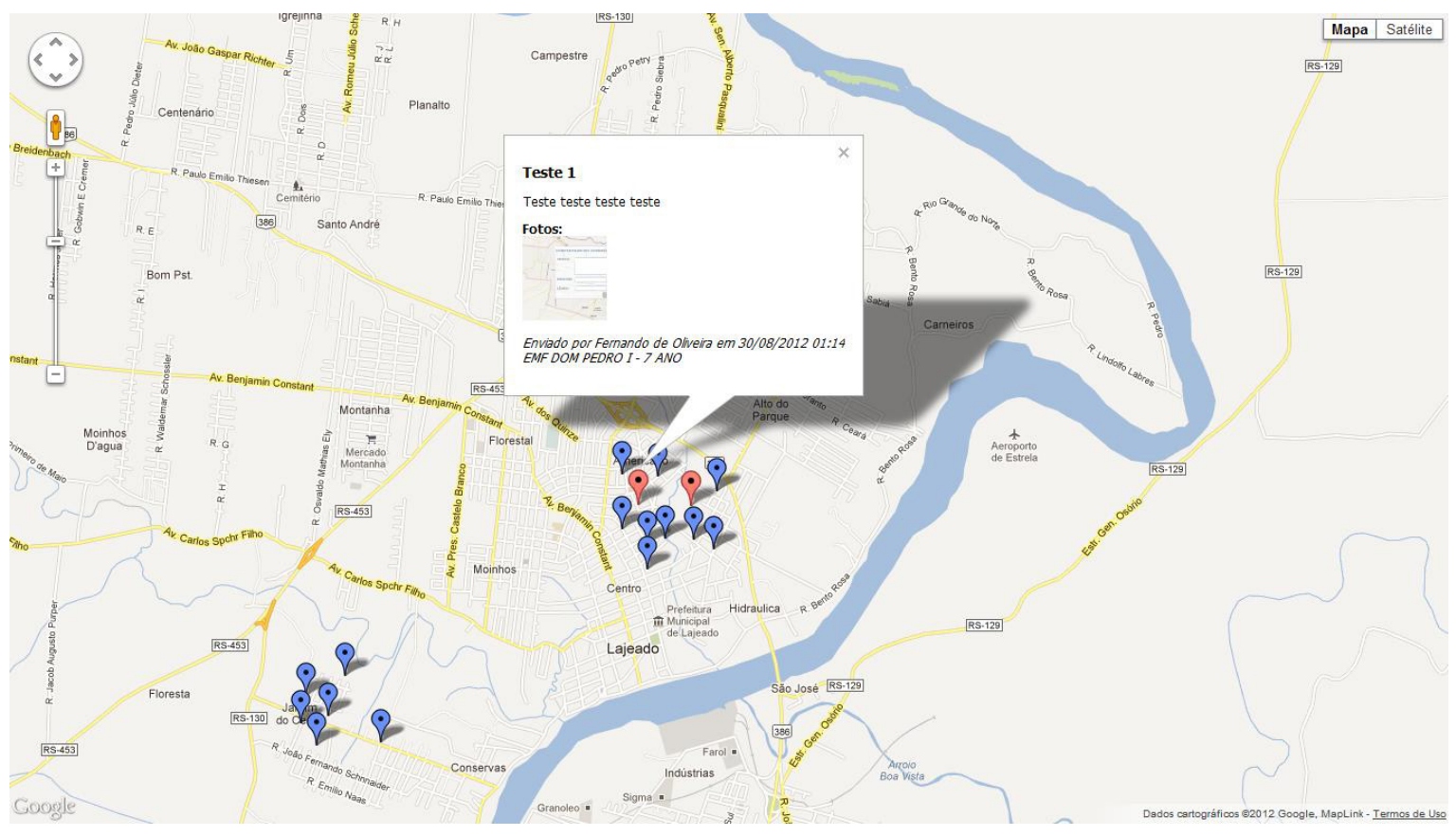

Fonte: OLIVEIRA, 2013.

pelos professores da cidade. Pensando em prática didática com interatividade criamos um quebra-cabeças onde as peças eram o contorno de cada bairro e cada uma tinha informações e imagens referentes ao lugar. A ideia evoluiu também com a criação de uma wiki que traria a contribuição dos alunos sobre seu bairro. $\mathrm{Na}$ prática, a wiki tinha certas limitações em algumas escolas, pois era preciso um espaço no servidor da prefei- tura ou outro particular. Estando pronto, o OA foi distribuído entre as escolas da rede municipal e aplicado pelos professores de informática e Geografia.

Partiu-se deste ponto para a arquitetura do objeto de aprendizagem Lajeado Virtual. Usamos como imagem de fundo o mapa centralizado a partir do município de Lajeado ${ }^{8}$. 0 mapa, já bastante difundido e conhecido na internet, é do servidor Google. Nele en- 
contramos ferramentas que vão além das nossas necessidades. Um exemplo é a imagem de satélite, onde o aluno pode reconhecer a partir da visão vertical e oblíqua o lugar onde mora; e o outro exemplo é o Google Street View, no qual imagens em 360 graus mostram a cidade a partir do ângulo da rua. Com essas inovações, tecnologias que surgem no século XXI, o aluno tem a atratividade convidando-o a dar um passeio pelos lugares que conhece no cotidiano, e outros que ouve falar na escola, a partir da tela do computador.

Com essas inovações tecnologias que surgem no século XXI, o aluno tem a atratividade convidando-o a dar um passeio pelos lugares que conhece no cotidiano, e outros que ouve falar na escola, a partir da tela do computador. Os professores passam a ter um espaço onde podem aprovar, editar ou excluir as postagens dos alunos. É nesse espaço que o professor tem o controle sobre as publicações, catalisando as mesmas e controlando a veracidade e os termos usados nessas.

A pesquisa e a curiosidade nos levam a descobrir websites que são realmente incríveis. Encontrei, nos andares pedagógicos e nas pesquisas na internet, uma ferramenta com rara utilização pedagógica e potencialmente classificada como OA: Maps Engine, do Google, e funciona a partir da base de mapas do Google com possibilidade de editar informações georreferenciadas sobre ele. Na sala de aula, o mais próximo que chegaríamos desta atividade seria projetar um mapa no quadro e rabiscar sobre ele informações do município. Que de- pois seriam apagadas e a prática não duraria mais que dois períodos.

Em uma aplicação com alunos do 2o ano do Ensino Médio de uma escola de ensino privado de Lajeado/RS, o resultado foram os mapas apresentados na Imagem 3 e na Imagem 4 . No formato em que se apresenta (impresso), temos fatores limitadores bem prováveis: não é possível ampliar o mapa, acessar as informações que cada um dos pontos marcados trás, nem mesmo substituir a imagem de mapa de fundo por uma imagem de satélite, terreno, mapa político, mapa físico, entre outros. Porém, o mapa está disponível na web para consulta ${ }^{9}$. A opção de editá-lo está bloqueada, pois tínhamos combinado um prazo de realização da tarefa.

Esta atividade contempla a web 2.0, pois permite dinâmicas como autoria do aluno, colaboração a partir da edição e até mesmo exclusão de informações dos colegas, interatividade a partir da análise do que um colega inseriu de informação. Mas o mais importante, diante da questão geográfica, é a possibilidade de organizar as informações em um mapa.

Georreferenciar uma informação, para a Geografia, é básico. Dizer onde se encontra determinada indústria, serviço ou comércio, como é o caso dos mapas que os alunos criaram, permite observações acerca da Geografia local, conectando o saber do aluno com as características globais, estabelecendo relações e interpretando o mundo a partir da sua experiência de vida (COSTELLA; REGO, 2011).

Imagem 3 - Resultado da atividade realizada no Google Maps Engine.

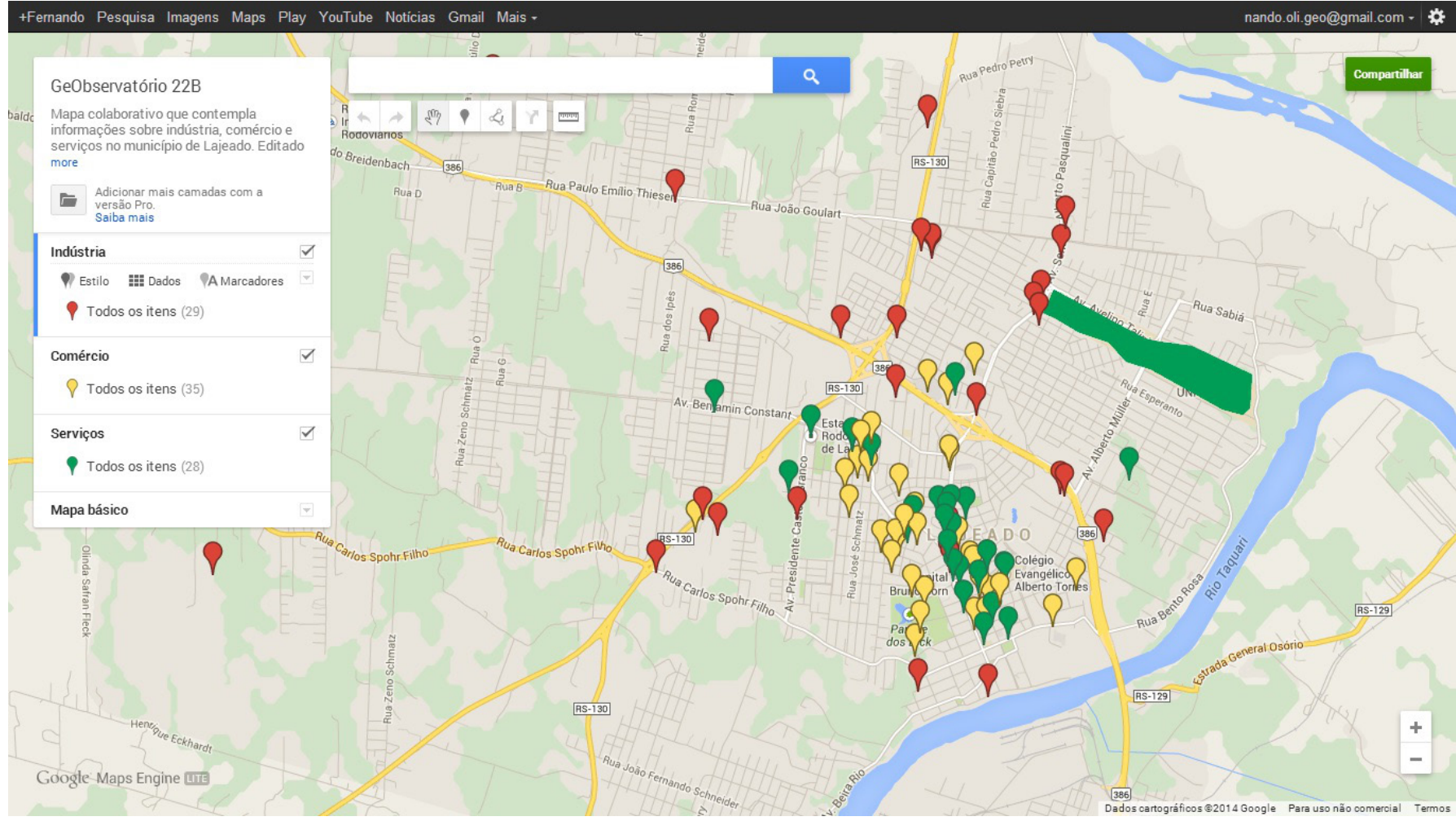

Fonte: OLIVEIRA, 2014. 


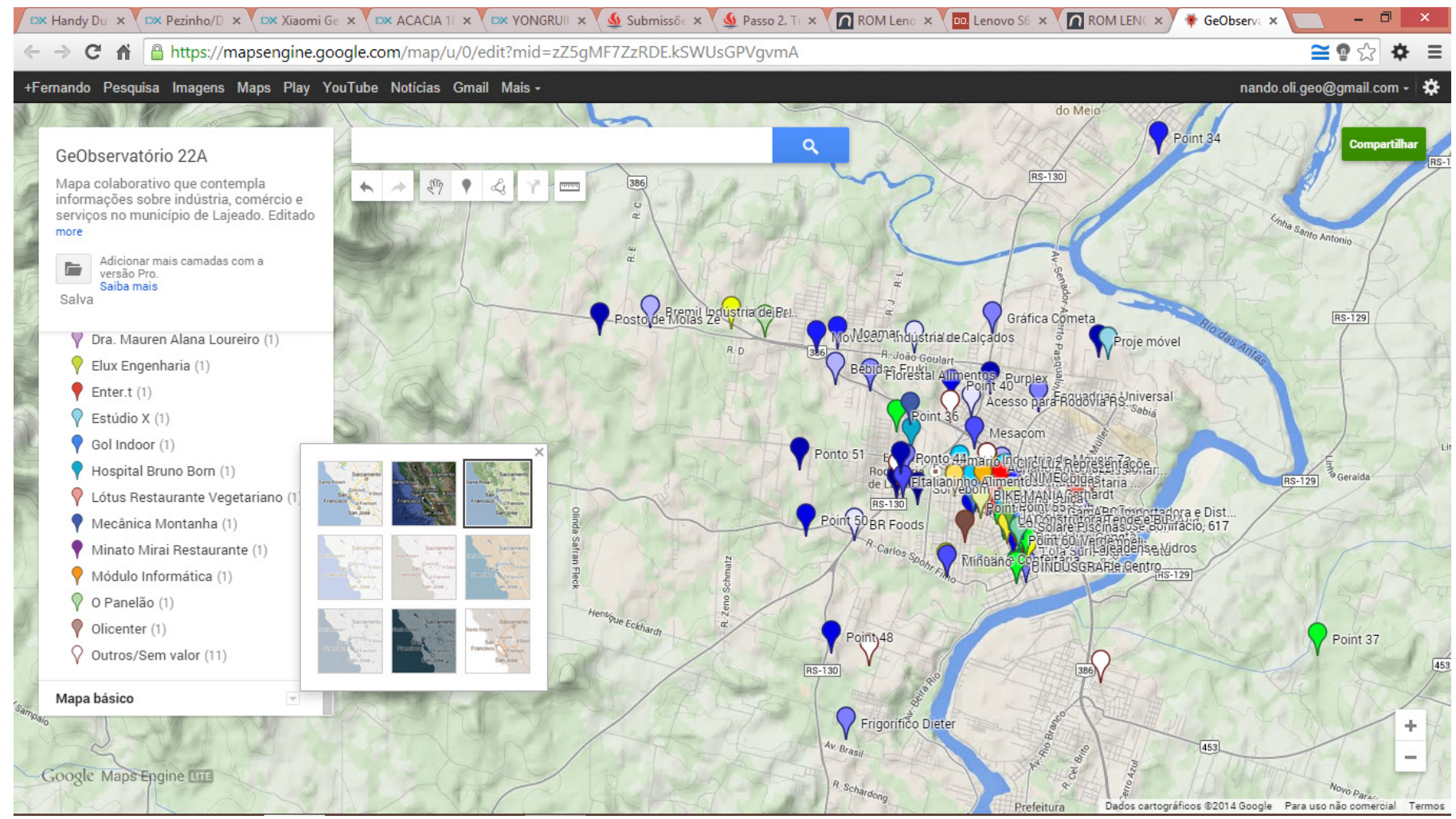

Fonte: OLIVEIRA, 2014

É possível ver algumas diferenças nos mapas, cada qual compilando informações criadas por uma turma diferente. No primeiro, o modo de organizar as camadas (comércio, serviços, indústria) permite uma visualização mais rápida e menos confusa, quando no segundo a mistura de cores sem definição por camada confunde o olhar.

\section{Das considerações finais}

As intenções da construção destes OAs são apenas de contribuição para inovação de práticas didáticas de Geografia, a fim de alcançar uma sala de aula interativa, conectada as praticas cotidianas de nossos alunos do século XXI. A partir disso pensamos na construção de OAS que tivesse forte apelo de aquisição entre professores da cidade de Lajeado/RS, para isto buscamos junto a eles os conteúdos trabalhados em sala de aula, as vontades diante das possibilidades do meio digital, e as necessidades da digitalização de conteúdos pouco abordados em sala de aula. Assim a proposta é de uma interação entre o aluno e a máquina, num conteúdo virtual, que permite ao primeiro a escolha do destino da sua construção de conhecimento e condizente com as linguagens de programação.

Os OAs são poderosas ferramentas para auxiliar o processo de apreensão de conteúdos sobre a cidade pelos alunos. Com elas, é possível criar um ambiente virtual no processo ensino/aprendizagem, tornando-os ferramentas que aceleram esse processo e que facilitam ao professor na mediação do processo de ensinar. Do mesmo modo, os OAs podem ser considerados uma ferramenta cognitiva para buscar uma qualificação do processo ensino/aprendizagem.

Outras vantagens deste recurso didático esta por ser altamente dinâmico e interativo; de evidenciar ao aluno seu potencial como construtor de seu próprio conhecimento; desenvolver-se nas modalidades presenciais, a distancia ou hibrida; durabilidade, facilidade para atualização, flexibilidade, interoperabilidade, modularidade, portabilidade, entre outras; passiveis de combinação com outros objetos educacionais ou qualquer outra mídia digital (vídeos, imagens, áudios, textos, gráficos, tabelas, tutoriais, aplicações, mapas, jogos educacionais, animações, infográficos, páginas web) por meio da hiperconexão.

Estes OAs propostos já estão sendo usados em algumas escolas da cidade de Lajeado/RS, com atividades nem imaginadas por nós, apenas para exemplificar relatamos dois modos de usos diferentes. Numa sala de aula de geografia foi solicitado aos alunos um roteiro pelo mapa apontando pontos que já visitariam no município, como a Prefeitura, Biblioteca Municipal, a Casa De Cultura, o Jardim Botânico, entre outros pontos. Outro exemplo é de mostrar que estes OAs tornou-se interdisciplinar ao ser utilizado por outras disciplinas, como a Bilologia, a professora solicitou aos alunos pesquisarem no bairro Conservas pontos onde o lixo é depositado incorretamente, compartilhando as fotos no mapa. As duas atividades já denotam um tom multidisciplinar aos OAs, tornando-se provavelmente uma ferramenta de uso abrangente e socialmente inclusiva.

Assim, há urgência em buscar conexões entre as práticas escolares e cotidianas dos alunos para que se 
estabeleçam materialidades de funções: os alunos sentirem a sedução da busca do aprender e os professores sentirem a motivação do ensinar. Estes imperativos certamente permitirão à escola desempenhar sua função fundante: ensinar pra vida! Acredito estar na tecnologia um dos elos desta conexão!

Mas ainda, tem muitos impeditivos que completam o atual quadro da educação brasileira: As políticas públicas, com suas mazelas que vão desde a corrupção até o planejamento de uma educação para a formação de mão-de-obra de qualidade mediana, passando por problemas estruturais como uma baixa qualidade do sinal de banda larga, porém com grandes investimentos nas áreas da informática na educação com a instalação de laboratórios de informática - mesmo sem preparar os docentes para usá-los; a formação de professores, com suas carências no aparelhamento das universidades e sistemas de seleção, e a falta de preparo para lidar com tecnologias inseridas de cima para baixo pelos administradores das escolas; e os alunos, geração de cérebros já dotados de capacidades além do conhecimento dos professores, afoitos e individualistas, que pensam no instantâneo como momento de vida e têm no consumismo o afago que os pais não dão em casa.

Historicamente, o Brasil traz em seu currículo uma pesquisa forte na área da informática para a educação, investindo em formação de mão-de-obra para lidar com a tecnologia. Porém, a formação de professores que saibam lidar com as tecnologias é pífia. Vemos isso nos números que esta pesquisa traz e também na surpresa dos alunos (que absorvem como novidade) quando o professor sugere uma tarefa onde será utilizada uma TIC.

Observando os horizontes já alcançados em termos de políticas públicas para a informática na educação, avalio como um impulso muito forte no início da década de 1990, quando a informática não tinha grande potencial, e que paulatinamente foi perdendo forças para as grandes companhias de comercialização de conteúdo web.

Sabemos que a tecnologia surge rapidamente, e evolui ainda mais rápido. Porém, muitas delas não vingam, se tornam obsoletas. Um caso clássico é o Second Life, considerado por muitos à época em que foi lançado como o padrão de vida virtual, uma vida que substituiria a vida real para a concretização de negócios, reuniões, lojas entre muitos outros.

Se levarmos em conta a evolução tecnológica que existe atualmente (e que em seguida já será considerada ultrapassada), podemos considerar esta pesquisa obsoleta, e os meios pelos quais ela se efetivou também obsoletos. 0 uso de OAs, de redes sociais... tudo isto poderá ser apenas página da história. E o que fica disso tudo? Tenho a certeza de que, independente da tecnologia criada, da plataforma existente, das relações sociais e dizeres culturais, deve o professor estar atento a tudo isso e adaptar sua aula para se aproximar da realidade de seu aluno, tornando o processo de ensino e aprendizagem uma experiência de vida, não um acumulado de informações analógico.

De nada adianta o professor criticar negativamente as aplicações que se dão à informática, para auxiliar ou simplesmente "empurrar" laboratórios de informática às escolas, se não houver dedicação em entender e utilizar tais possibilidades.

Enfim, penso que a educação hoje carece muito mais de uma evolução da escola, da estrutura escolar, dos elementos que a conduzem, do que do professor/ funcionário, mantido como tal (um objeto contratado, pago para tal fim). A docência, atemorizada pela instabilidade do emprego, pela necessidade do salário, é percebida na lacuna que desinteressa alunos, pais e professores pela escola em seu atual modelo. Utilizo as palavras de Kaercher (2011, p. 133) para amortizar a dureza da profissão, pois foca na existência de um interesse diferente:

que minha aula toda não está em livros, mas na vida dos alunos. A vida dele é (deveria ser) o conteúdo, é dela que tiro minhas aulas. É difícil, porque antes preciso entender como eles pensam e vivem, uma cultura totalmente diferente. Que sensibilidade! De novo o choque, a necessidade de que eu, professor, me descentre de minhas ideias e práticas para ver o outro não como uma ameaça, não com um olhar condenatório, moralista e correcional. Difícil afinal, temos nossas ideias porque acreditamos que elas são corretas e têm servido para levarmos nossa vida adiante.

O saber de nada se vale se não houver sabedoria para passa-lo adiante. Os receios de uma educação não formal, longe das paredes tradicionais, parecem assustar aqueles que gerem a educação - diretores, coordenadores. A prática didática deve, sim, explorar novos recursos, tornar leve o aprendizado, buscar o espaço de vivência do aluno. Conquistá-lo a partir do ambiente em que ele se acostumou a praticar suas atividades de lazer, leva-lo a descobrir que há interesse em sua vida, não apenas em preencher o vazio dos seus pensamentos com conteúdos que terminam na próxima avaliação em sala de aula.

\section{Referências}

ASSMANN, Hugo. Redes digitais e metamorfose do aprender. Petrópolis: Vozes, 2005.

BEHAR, Patrícia Alejandra. Modelos pedagógicos de educação à distância. Porto Alegre: Artmed, 2009.

CAVALCANTI, Lana. Geografia Escolar e acidade: ensaios sobre o ensino de geografia para vida urbana cotidiana. Campinas: Papirus, 2008.

CASTROGIOVANNI, Antonio Carlos; COSTELLA, Roselane Zordan. Brincar e Cartografar com os diferentes mundos geográficos: alfabetização espacial. Porto Alegre: 
PUC/RS, 2006.

HANDA, J. K.; SILVA, J. B. G. "Objetos de Aprendizagem” (Learning Objects). Boletim EAD, Campinas, n. 43, jan. 2003.

KAERCHER, Nestor André. Conheça e revele-se estudando a cidade: experiências geopedagógicas para pensar nossa ontologia. In: CASTROGIOVANNI, Antonio Carlos; REGO, Nelson; KAERCHER, Nestor André (orgs.). Práticas Pedagógicas para o Ensino Médio. Porto Alegre: Penso, 2011.

SAMPAIO, Marisa Narcizo. Alfabetização Tecnológica
Do Professor. Petrópolis: Vozes, 2011.

SANTOS, Edméia. "Introdução". IN: Salto para o Futuro. Ano XXI, Boletim 03, p.5-10. http://tvescola.mec.gov.br. [Ultimo acesso, 10 agosto 2012].

SILVA, Marco (Org.). Formação de professores para docência online. São Paulo, Loyola, 2012.

TAROUCO, Liane M. R.; CUNHA, S. L. S. Aplicação de teorias cognitivas ao projeto de objetos de aprendizagem. Novas Tecnologias na Educação, Porto alegre, v.4, n. 2, p. 1-9, dez. 2006.

Abstract: This article was intended to show the learning objects to enable teaching activities in a online classroom in geography teaching of basic education with themes directed to the study of the city. The theoretical understanding has enabled this feature as an interactive tool between student and knowledge, which becomes producer of his knowledge. The results indicate the relevance of the use of learning objects in the classroom, not only for being a tool of wide operability in the daily practices of the students, but as increased student interest in pursuing and build knowledge about our routine.

Keywords: Learning objects, online teatching, city, Geography learning. 